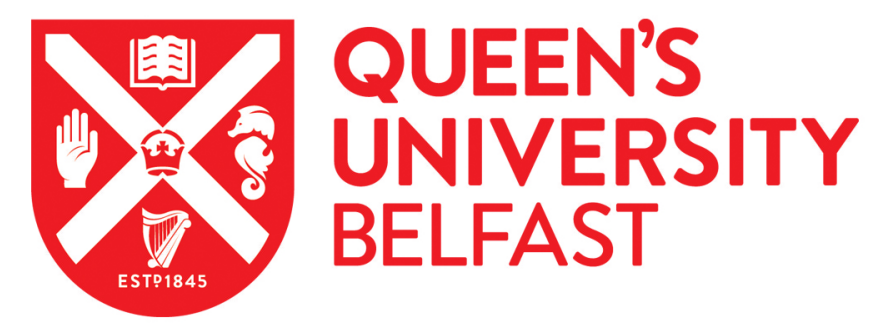

\title{
Chronic inflammation in CF airways - a persistent issue for A20
}

McCollum, K., El Banna, A., Ennis, M., \& Schock, B. (2016). Chronic inflammation in CF airways - a persistent issue for A20. Journal of Genetic Syndromes \& Gene Therapy. https://doi.org/10.4172/2157-7412.1000304

Published in:

Journal of Genetic Syndromes \& Gene Therapy

Document Version:

Publisher's PDF, also known as Version of record

Queen's University Belfast - Research Portal:

Link to publication record in Queen's University Belfast Research Portal

Publisher rights

(C) 2016 The Authors

This is an open access article published under a Creative Commons Attribution License (https://creativecommons.org/licenses/by/4.0/), which permits unrestricted use, distribution and reproduction in any medium, javascript:void(0); provided the author and source are cited.

\section{General rights}

Copyright for the publications made accessible via the Queen's University Belfast Research Portal is retained by the author(s) and / or other copyright owners and it is a condition of accessing these publications that users recognise and abide by the legal requirements associated with these rights.

Take down policy

The Research Portal is Queen's institutional repository that provides access to Queen's research output. Every effort has been made to ensure that content in the Research Portal does not infringe any person's rights, or applicable UK laws. If you discover content in the Research Portal that you believe breaches copyright or violates any law, please contact openaccess@qub.ac.uk. 


\title{
Chronic Inflammation in CF Airways - A Persistent Issue for A20
}

\section{McCallum K, El Banna A, Ennis M and Schock BC*}

Centre for Experimental Medicine, Queen's University of Belfast, Belfast BT9 7BL, UK

\begin{abstract}
Cystic Fibrosis (CF) is characterised by prolonged and exaggerated airways inflammation. Despite recent developments to overcome the underlying functional defect in CFTR (cystic fibrosis transmembrane conductance regulator); there is still an unmet need to reduce the inflammatory response. The NF-kB regulator A20 is a key target to normalise the inflammatory response and is reduced in CF. Here, we describe the plethora of functions of A20 as they apply to innate immune function within the airways. Pharmacological compounds can enhance A20 mRNA and protein expression, but we observed a blunted effect in CF primary epithelial cells. In CF cells pre-treatment with gibberellic acid (GA3) shows anti-inflammatory effects only in some patients. We show that cells with higher basal p38 expression respond with an increase in pro-inflammatory cytokines. Furthermore, all CF PNECs show increased p38 mRNA when stimulated in the presence of GA3. Our results suggest that those patients may benefit from therapeutics targeting p38.
\end{abstract}

Keywords: Cystic fibrosis; Airway inflammation; A20 protein; NF$\kappa \mathrm{B} ; \mathrm{p} 38$

\section{Introduction}

The outlook for Cystic Fibrosis (CF) patients has dramatically improved over the last 10-20 years, mostly due to rigorous antibiotic treatment. The average life expectancy is now 40 years [1] and a child born with CF in 2016 is predicted to well live beyond 50 [2]. However, airways infection and the subsequent inflammation are deleterious for CF patients. Infection with Pseudomonas aeruginosa ( $P$. aeruginosa) still represents the leading cause of chronic inflammation, lung function decline and ultimately death in CF patients [3]. Recently drugs have been approved that target the modified protein CFTR (cystic fibrosis transmembrane conductance regulator) improving expression and function of CFTR.

The small molecule CFTR potentiator Ivacaftor enhances the function of CFTR which reaches the cell membrane (class III mutation, e.g. Gly551 Asp-CFTR) [4] and its use in CF patients with the Gly551Asp mutation has improved lung function and quality of life [5]. Whilst the development of Ivacaftor (Kalydeco) is promising, this mutation accounts for only $5 \%$ of CF cases. A greater clinical benefit may be seen through the development of CFTR correctors that particularly target the most common class II mutation, Phe508del. The CFTR corrector, Lumacaftor, helps to bypass the degradation of Phe508del-CFTR. Once at the cell membrane, potentiator treatment can enhance the function of this CFTR. Randomised clinical trials using dual therapy (corrector/potentiator, Orkambi) reported an improvement in FEV1 (forced expiratory volume in one second) and reduced frequency of pulmonary exacerbations, hospitalization and use of intravenous antibiotics in patients homozygous for Phe508del [6]. However, although successfully improving expression and function of CFTR, airway inflammation was not reduced. In CF patients aged 6 years and above with Gly551Asp-CFTR, 6 months of treatment with Ivacaftor did not reduce inflammatory markers in sputum such as IL-1, IL-6 and IL-8 [7] and heterogeneous responses to the corrector/potentiator treatment have been reported in patients homozygous for Phe508delCFTR [8]. This suggests that CFTR correction/potentiation may not directly improve the underlying compromised immune response, thus there is still an unmet need to normalise the inflammatory response in $\mathrm{CF}$ airways. Here we focus on the regulation of NF- $\mathrm{kB}$-driven lung inflammation in CF by the negative regulator A20.

The ability to respond to pathogens is critical for health and survival and pathogens are identified by epithelial and immune cells through pattern recognition molecules, namely the toll-like receptors (TLRs).
Several studies [9-11] have shown altered TLR-4 expression in CF airway epithelial cells, leading to increased expression of inflammatory cytokines [12]. Such overall deranged immune response in CF is largely driven by the transcription factor NF- $\mathrm{kB}$ and a lack of intrinsic downregulation of NF- $\mathrm{kB}[13,14]$.

The ubiquitinating/deubiquitinating enzyme A20 has recently become a subject of great interest due to its identification as a multifaceted modulator of immunity and disease and its function as one of the key regulators of NF- $\kappa B$ activation [15]. A20 was initially identified as a tumour suppressor gene [16], but polymorphisms and reduced expressions have since been implicated in chronic inflammatory conditions such as inflammatory bowel disease, systemic lupus erythematosus, type 1 diabetes, psoriasis, rheumatoid arthritis and multiple sclerosis, where A20 could serve as a susceptibility gene/ biomarker of disease development $[17,18]$.

Basal expression of A20 is low in most cell types; however, A20 is rapidly induced upon stimulation of $\mathrm{NF}-\mathrm{\kappa B}$ [18]. Increased expression of A20 is associated with an inhibition of NF- $\mathrm{kB}$ as shown in mouse embryonic fibroblasts [19]. A20 deficient mice develop severe, systemic inflammation without stimulation as they are not able to terminate NF$\kappa \mathrm{B}$ signalling resulting in premature death [20].

\section{A20 in the airways}

In the airways, stimulation with bacterial lipopolysaccharide (LPS) and peptidoglycan PGN upregulates A20 mRNA in primary cultured airway epithelial cells and H292 cells and inhibits TLR2 and TLR4 mediated IL-8 synthesis [21]. Enhanced A20 mRNA expression occurs following infection of mice with $P$. aeruginosa [22] We have previously shown that the prolonged NF- $\kappa B$ driven inflammatory response in $\mathrm{CF}$ airway epithelial cells is associated with reduced expression of A20 [23]

*Corresponding author: Schock BC, Centre for Experimental Medicine, Queen's University of Belfast, Medical BiologyBuilding, 97b Lisburn Road, Belfast, UK, BT9 7BL, Tel: +44 (0) 289097 2258; Fax: +44 (0) 2890 972671; E-mail: b.schock@qub.ac.uk

Received July 14, 2016; Accepted August 12, 2016; Published August 19, 2016

Citation: McCallum K, El Banna A, Ennis M, Schock BC (2016) Chronic Inflammation in CF Airways - A Persistent Issue for A20. J Genet Syndr Gene Ther 7: 313. doi: 10.4172/2157-7412.1000313

Copyright: (c) 2016 McCallum K, et al. This is an open-access article distributed under the terms of the Creative Commons Attribution License, which permits unrestricted use, distribution, and reproduction in any medium, provided the original author and source are credited. 
and most importantly this lack of A20 correlates with reduced lung function in patients with CF [24]. Onose et al. described virus induced induction of A20 in human bronchial epithelial cell lines and mouse lung homogenates. Furthermore, transient overexpression of A20 in epithelial cell lines inhibited NF- $\kappa \mathrm{B}$ activation and inflammation following influenza infection [25]. However, in in vivo experiments in mice selective A20 deficiency in Clara cells appears to protect against influenza A virus infection with reduced host innate and adaptive immune responses and lung damage, which was not due to decreased viral replication in these cells. In contrast, mice in which A20 was selectively knocked down in myeloid cells/macrophages show increased $\mathrm{NF}-\kappa \mathrm{B}$ and IRF3 driven inflammation in response to influenza infection, suggesting a cell type specific effect of A20 or an additional late response effect (adaptive immunity) [26]. However, in response to lethal doses of influenza A20 knockout mice appeared protected [27].

\section{The diverse functions of A20}

The action of A20 within inflammatory NF- $\mathrm{kB}$ activation pathways has been extensively investigated. Upon activation of the canonical NF$\kappa B$ pathway through LPS binding to TLR4, A20 acts as an endogenous regulator on the E3 ligase TRAF6 to reduce NF- $\mathrm{KB}$ activation and subsequent translocation [18]. Signalling pathways initiated by TNFa and IL- $1 \beta$ leading to NF- $\kappa$ B activation are also regulated by A20 [15]. Furthermore, A20 negatively regulates the TLR induced inflammasome and thereby the release of IL-1 (and other members of the IL-1family) [28] and activation pathways of IL-17R, NOD receptors, RIG-I receptor and T-cell receptor [29], emphasising its key role in regulating inflammation (Figure 1).

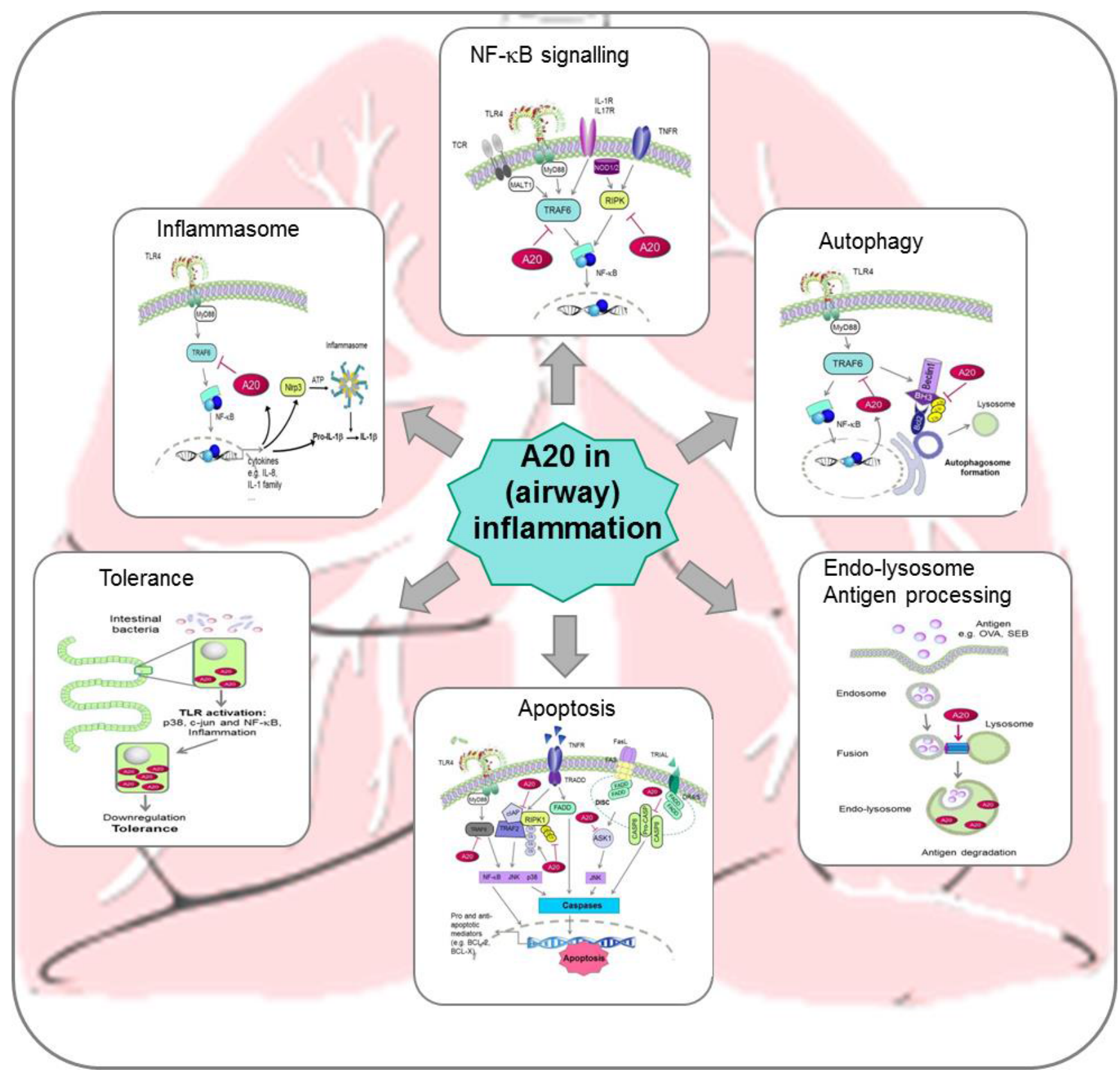

Figure 1: Summarises the main functions of A20 in the airways within the inflammatory context. 
A20 is also involved in the promotion of tolerance to (commensal) bacteria. In the rat intestine A20 prominently localizes to the luminal side of the villus enterocytes, while lower (more protected) parts of the crypts display relatively low levels of A20 [30]. In culture, repeated stimulation of rat enterocytes (e.g. IEC6/18 cells) with LPS or of human monocytic THP-1 cells with Pam3CSK4, TNF- $\alpha$ or IL- $1 \beta$ results in an inhibition of subsequent LPS-induced activation of p38, c-Jun and NF- $\kappa \mathrm{B}$ lasting up to $28 \mathrm{~h}$ in proliferating and over $72 \mathrm{~h}$ in stationary cultures [30] (Figure 1). Moreover, antibiotic treatment of rats led togut decontamination' and reduced A20 levels in the epithelium [30].

Furthermore, A20 appears to be important in endo-lysosome formation and therefore may play an important role in antigen processing. In cultured human intestinal epithelial cells (Caco-2 and HT-29), A20 is needed for fusion of endosomes and lysosomes and therefore the degradation of microbial products such as SEB and exogenous allergens such as ovalbumin [31,32]. A20-deficient Caco-2 cells show significantly lower endo-lysosome formation and subsequent transport of OVA to the basolateral side ultimately conserving antigenicity [32]. Therefore, during inflammation, A20 may contribute to the tethering of the endosome to lysosome itself, but the mechanism by which A20 contributes to membrane fusion needs further investigation. Moreover, mice lacking A20 specifically in their intestinal epithelial cells do not show spontaneous intestinal inflammation but exhibited hyper-responsiveness to TNF-induced apoptosis, resulting in a breakdown of the intestinal barrier permitting commensal bacterial to infiltrate and cause systemic inflammation [33] (Figure 1). Commensal bacteria in the lung may also promote tolerance in airway epithelial (and immune cells) but lack of A20 in CF airway epithelial cells, accelerated by frequent antibiotic therapy may prohibit appropriate development of tolerance. Furthermore, stimulation of $\mathrm{CF}$ airway epithelial cells with LPS results in TLR4 being preferentially recycled and not targeted to endo-lysosomal degradation [12], which may contribute to the repeated stimulation of the epithelium. Equally, processing of inhaled antigens together with a reduced barrier function of the airway epithelium would significantly impact the inflammatory responses in atopic asthma. Similarly, A20 is important in controlling TLR4 induced autophagy. For instance, ubiquitination of Beclin1 and subsequent oligomerization activates of PI $3 \mathrm{KC} 3$ and promotes the formation of autophagosomes. In murine macrophages (RAW 264.7) and human embryonic kidney cells (HEK 293T), A20 limits TLR4 induced autophagy by deubiquitinating TRAF6 and Beclin1 [34] (Figure 1).

However, in high A20 mRNA expressing murine F4/80hi macrophages (spleen, peritoneum and kidney) NF- $\kappa B$ activation is enhanced by autophagic depletion of A20. This allows these macrophages to release chemokines for the recruitment of neutrophils.

Finally, A20 plays an important role in apoptosis, a process of cell suicide in response to a variety of stimuli including infections, necessary to maintain immune and tissue homeostasis. Apoptosis is initiated through one of two pathways: Intrinsic (intracellular signals) or extrinsic (receptor ligand binding) with both pathways converging on the same set of executioner caspases. During intrinsically induced apoptosis, A20 can inhibit apoptosis and promote cell survival through its modulation of TNFa induced apoptosis independent of NF- $\kappa B$ termination [15], which in part may be mediated by direct binding to cIAP $1 / 2$ and preventing the association between TRAF2 and RIP1 [35]. Furthermore, in cell lines (e.g. HeLa, HEK293 and MEFs) and $\beta$-cells in type 1 diabetes A20 can suppress c-jun $\mathrm{N}$-terminal kinase (JNK) through ubiquitination/degradation of the apoptosis signal regulating kinase 1 (ASK1), while TNFa stimulation in the absence of A20 results in persistently active JNK [36,37]. However, pro-apoptotic functions of A20 have also been identified, mostly likely due to the termination of NF- $\kappa \mathrm{B}$ and subsequent loss of anti-apoptotic proteins, BCL-2 and BCL-X [29]. This suggests that the effect of A20 is a balance between its own innate anti-apoptotic functions and the expression of NF-kB mediated anti-apoptotic proteins which may be hindered through repression by A20. Extrinsically induced apoptosis may also be regulated through A20. TRAIL (TNF related apoptosis inducing ligand) bound to death receptors DR4/5 or FasL bound to Fas induce pro-apoptotic signalling and recruitment of FADD (Fas associated protein with death domain) and caspase-8. This leads to the formation of the death inducing signalling complex (DISC). A20 is recruited to the DISC, overall inhibiting the downstream activation of caspase- 8 [38,39].

Taken together the critical contribution of A20 in immune tolerance (intestinal and pulmonary), antigen processing, epithelial barrier function and the well-established role in inflammation and apoptosis, A20 has an essential role in maintaining immune homeostasis. Therefore, the apparent lack of A20 described in epithelial cells of patients with CF and asthma $[23,40]$ has important implications for the overall immune responses in these chronic airway diseases. Not surprisingly, A20 has recently been identified as a target enzyme for new anti-inflammatory drugs $[41,42]$.

\section{A20 as a target for anti-inflammatory drug development in CF}

In line with the bacterial induction of immune-regulatory A20, earlier work suggested the benefit of A20 induction by inactivated bacteria ( $P$. aeruginosa) in allergic airway inflammation [43]. Using airway epithelial cells (cell lines and primary cells from control subjects), we have previously shown that pharmacological induction of A20 through the plant diterpenoid gibberellin $\left(\mathrm{GA}_{3}\right)$ is antiinflammatory [42]. Furthermore, using an advanced bioinformatics approach that established the link between disease-specific gene expression and the gene modification through already licensed drugs, statistically significant connections Map (sscMap) [44] we were able to predict drugs already licenced for the use in humans, which through the process of drug repositioning could be made available to CF patients. Our candidate drugs predicted to increase A20 gene expression were quercetin and the macrolide ikarugamycin. However, although successful in non-CF airway cells, CF epithelial cells showed an overall blunted (delayed and reduced) response with respect to A20 induction and the subsequent reduction in inflammation [41].

Using cell lines (16HBE14o- and CFBE41o-), gibberellin (GA, pre-treatment showed a similar reduction in IL-8 release in non-CF and CF epithelial cells. However, CF primary nasal epithelial cells (PNECs) compared to non-CF PNECs showed an individually diverse response, with some patients' cells showing a reduction in LPS induced IL-8 release in response to $\mathrm{GA}_{3}$ treatment, while others showed no response or a higher release of IL-8 (Figure 2). CF PNECs also showed a blunted response with respect to A20 mRNA induction and p65 mRNA reduction in response to $\mathrm{GA}_{3}$ treatment compared to non-CF PNECs ().

To further examine the observed pro-inflammatory effect of $\mathrm{GA}_{3}$ in CF PNECs, we determined p38 mRNA in CF and non-CF PNECs. Figure 3 shows p38 mRNA expression in $\mathrm{GA}_{3}$ pre-treated CF PNECs and Table 1 shows selected individual data form the same CF epithelial cultures. Compared to non-CF PNECs, CF PNECs show increased basal and stimulated p38 mRNA expression (4 h LPS). Pre-incubation 

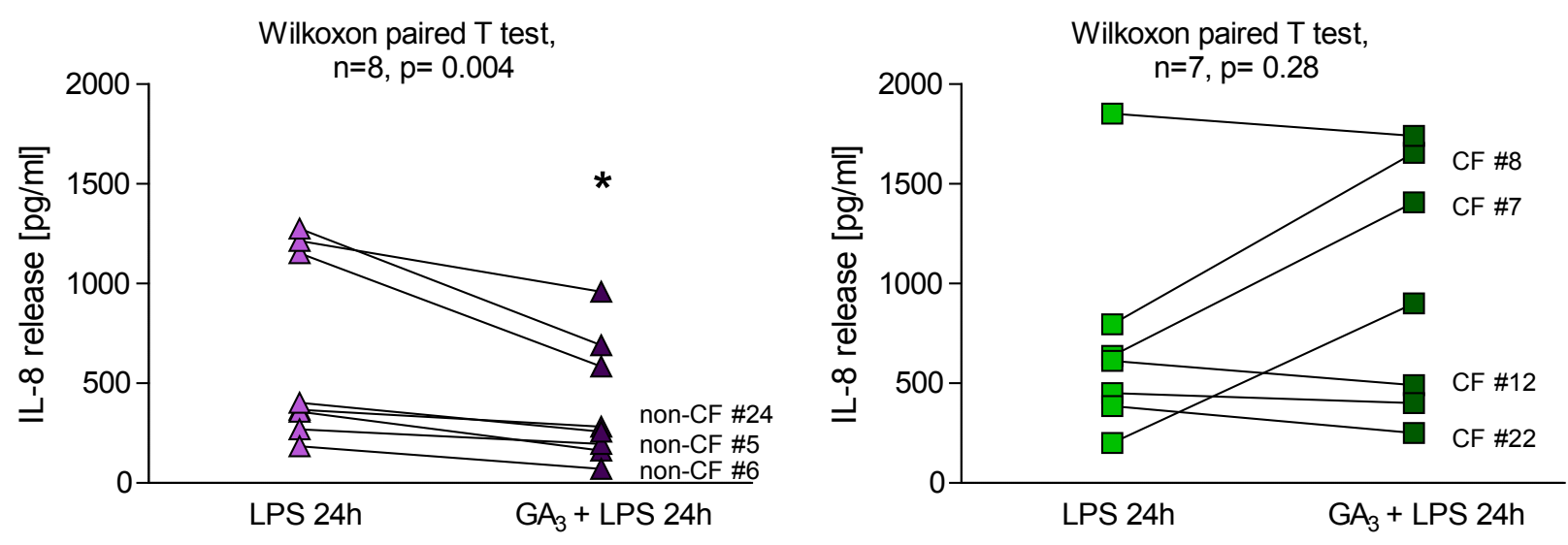

Figure 2: II-8 release from non-CF (purple) and CF (green) primary nasal epithelial cells stimulated with LPS (10 $\mu \mathrm{g} / \mathrm{ml})$ in the presence or absence of gibberellin GA3 $(30 \mu \mathrm{m})$.

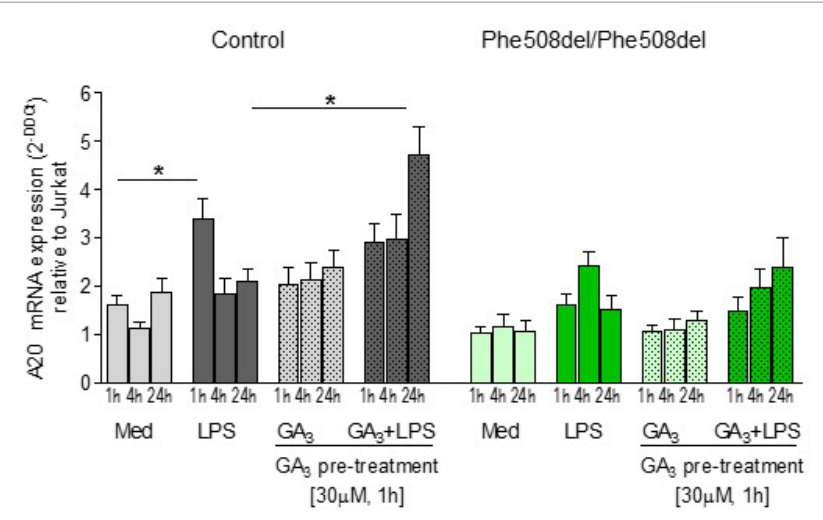

Kruskal-Wallis Test: non-CF: $n=7$, overall $p=0.0003$ CF: $n=6$, overall $p=0.02,{ }^{\star} p=0.05$ as indic ated

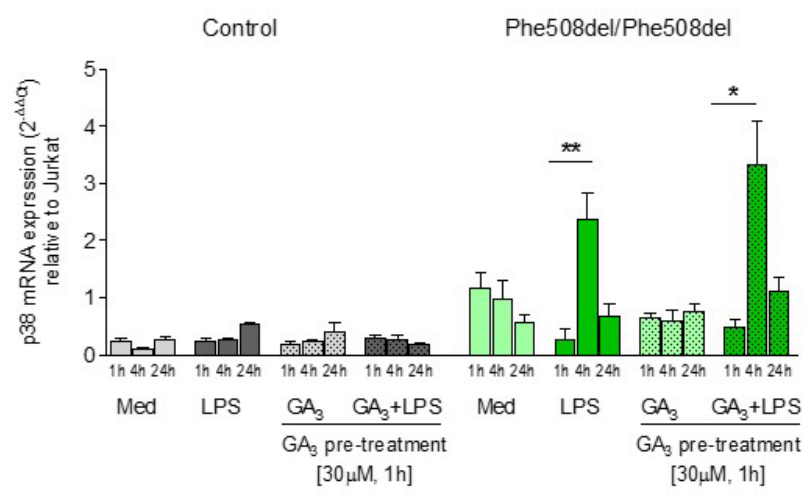

Kruskal-Wallis Test: non-CF: $n=5$, overall $p=0.011, C F: n=4$, overall $p=0.002,{ }^{*} p<0.05$ and ${ }^{* *} p<0.01$ as indicated

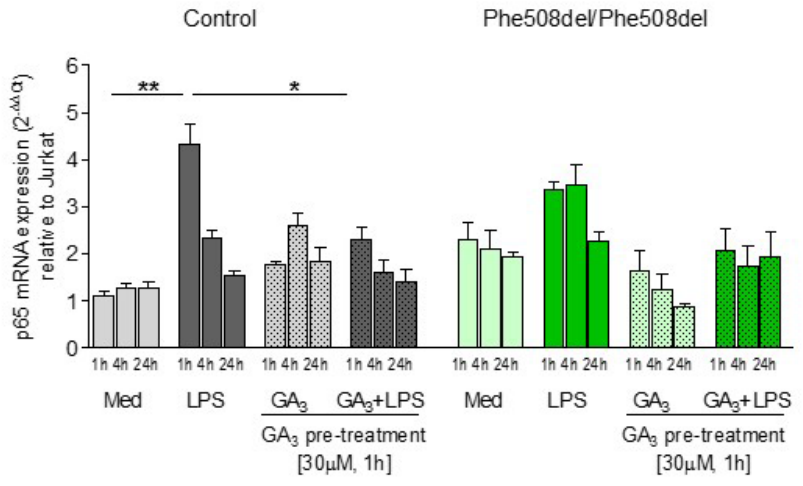

Kruskal-Wallis Test: non-CF: $n=5$, overall $p=0.0001, C F n=5$ : overall $p=0.004,{ }^{*} p<0.05$ and ${ }^{* *} p<0.01$ as indic ated

Figure 3: A20, p65 and p38 mRNA expression in non-CF (grey) and CF (green) primary nasal epithelial cells stimulated with LPS (10 $\mu \mathrm{g} / \mathrm{ml}$ ) in the presence or absence of gibberellin GA3 $(30 \mu \mathrm{m}, 1 \mathrm{~h})$.

of cells with gibberellin alone did not change p38 mRNA expression. When investigating the response of selected PNECs individually, we observed two different response types of CF PNECs, those in which the pre-treatment with gibberellin lead to an increase of IL-8 release $(\mathrm{CF} \# 7,8,157)$ and those which showed a decrease in IL-8 release similar to non-CF cells $(\mathrm{CF} \# 12,14,34)$. Analyses of p38 mRNA in these cells revealed that those in which gibberellin had a pro-inflammatory effect were PNECs with the higher basal p38 expression, while those which responded to gibberellin with a reduction in IL-8 had lower basal p38 mRNA expression. Table 1 shows IL-8 (pg/ml, stimulated with LPS in the presence and absence of $\mathrm{GA}_{3}$ ), p38 mRNA expression (basally and $4 \mathrm{~h}$ after LPS, when expression peaks, in the presence and absence of $\mathrm{GA}_{3}$ ) as well as A20 mRNA expression (basally and $1 \mathrm{~h}$ after LPS, in the presence and absence of $\mathrm{GA}_{3}$ ) of selected CF and non-CF PNECs. CF 


\begin{tabular}{|c|c|c|c|c|c|c|c|c|c|}
\hline & \multicolumn{3}{|c|}{ IL-8 [pg/ml] } & \multicolumn{3}{|c|}{ 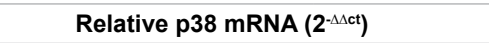 } & \multicolumn{3}{|c|}{ 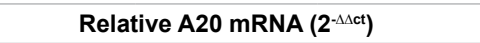 } \\
\hline & LPS $24 \mathrm{~h}$ & $\mathrm{GA}_{3}+\mathrm{LPS} 24 \mathrm{~h}$ & Change [\%] & Basal & LPS $4 \mathrm{~h}$ & $\mathrm{GA}_{3}+\mathrm{LPS} 4 \mathrm{~h}$ & Basal & $\mathrm{GA}_{3}+\mathrm{LPS} 1 \mathrm{~h}$ & Increase [\%] \\
\hline Non-CF\#5 & 269.65 & 195.21 & 72.389 & 0.44 & 0.39 & 0.35 & 1.66 & 3.21 & 193.3 \\
\hline Non-CF\#6 & 184.99 & 71.19 & 38.48 & 0.30 & 0.32 & 0.1 & 1.29 & 2.45 & 189.9 \\
\hline Non-CF\#24 & 401.85 & 257.69 & 64.13 & 0.21 & 0.29 & 0.52 & 1.49 & 3.54 & 209.4 \\
\hline CF\#7 & 637.81 & 1408.18 & 220.78 & 1.94 & 1.36 & 2.42 & 0.61 & 2.22 & 363.9 \\
\hline CF\#8 & 795.54 & 1656.92 & 208.28 & 1.02 & 2.53 & 3.26 & 0.38 & 1.09 & 286.8 \\
\hline CF\#157 & 356.30 & 1008.41 & 283.02 & 1.67 & 1.28 & 1.13 & 0.70 & 1.47 & 210.0 \\
\hline CF\#12 & 367.64 & 251.22 & 68.33 & 0.63 & 3.78 & 5.63 & 0.99 & 0.62 & 63.0 \\
\hline CF\#14 & 612.52 & 489.64 & 79.94 & 0.58 & 2.84 & 4.12 & 1.35 & 1.03 & 75.6 \\
\hline CF\#34 & 261.24 & 169.12 & 64.74 & 0.81 & 3.31 & 3.87 & 1.14 & 1.93 & 136.8 \\
\hline
\end{tabular}

Table 1: LPS induced IL-8 release $(24 \mathrm{~h})$ and p38 mRNA expression [basally and $4 \mathrm{~h}$ after stimulation from non-CF and CF primary epithelial cells. Cells were stimulated with LPS $(10 \mu \mathrm{g} / \mathrm{ml})$ in the presence or absence of gibberellin (GA3, $30 \mu \mathrm{m})$ and mRNA for p38 and A20 determined.

PNECs show a high variation in basal p38 mRNA expression (high: CF $\# 7, \# 8$, \#157; low: $C F \# 12, \# 14$, \#34), but they all are able to induce $\mathrm{p} 38$ in response to $\mathrm{GA}_{3}$, an induction that non-CF PNECs do not show (Table 1). Interestingly, when expressing the mRNA data as change from basal expression, CF cells with higher basal p38 mRNA levels (CF \#7, \#8, \#157) show the ability to increase A20 mRNA (\%) similarly to non-CF cells (Table 1). However, the data confirm reduced A20 induction in these CF PNECs and may suggest that other inflammatory pathways such as MAPK-p38 may play a role in the increased IL- 8 response to $\mathrm{GA}_{3}$.

\section{Materials and Methods}

\section{Cell culture and stimulations}

The bronchial epithelial cell lines 16HBE14o- (control) and CFBE41o-(CF, F508del/F508del) were obtained from Gruenert, UCSF, USA and cultured as described [23]. Primary nasal epithelial cells (PNECs) from healthy volunteers and CF patients (all F508del/F508del) were cultured as described [42]. Control participants did not have any acute airways disease at the time of sampling, or a history of any chronic airways inflammation. The Research Ethics Committee of Northern Ireland (07/NIR02/23) approved the study and all participants provided informed consent. Cells were exposed to gibberellic acid $\left(\mathrm{GA}_{3}\right.$, Sigma 63492, $30 \mu \mathrm{M}$ ) for $1 \mathrm{~h}$ prior to LPS stimulation (P. aeruginosa LPS, serotype 10, Sigma-Aldrich, L9143, $10 \mu \mathrm{g} / \mathrm{ml}$, upto $24 \mathrm{~h}$ ).

\section{Determination of LPS induced interleukin-8 release}

The concentrations of IL- 8 in cell-free culture supernatants were measured by a commercially available ELISA (PeproTech EC Ltd.) according to the manufacturer's instructions.

\section{Real time qPCR}

Total RNA was extracted using the GenElute" Mammalian Total RNA Miniprep Kit (RTN350, Sigma-Aldrich) and quantified on a Nanodrop (Thermo Scientific). Equal amounts of RNA (250 ng) were reverse transcribed into cDNA (High-Capacity cDNA Reverse Transcription Kit, Applied Biosystems"). Primers were designed using gene accession numbers and Primer3 open-source PCR primer design software and obtained from Invitrogen Ltd. (Paisley, UK) (p38 fwd: gcc aga aac tcc ttt tgc tg; p38 reverse: ctc ccc aaa cca aga agt ca). A20 and $\beta$-actin primer sequences previously described [42]. Relative expression to $\beta$-actin was calculated as $2^{-\Delta \Delta C t}$. Jurkat cell cDNA acted as an internal calibrator for all experiments and was used to determine differences in basal gene expression.

\section{Statistical analysis}

All data are presented as the means \pm SEM. Differences between groups were analysed using the Kruskal-Wallis non-parametric ANOVA with Dunn's post-test if the Kruskal Wallis test was significant $\left({ }^{*} \mathrm{p}<0.05,{ }^{* *} \mathrm{p}<0.01,{ }^{* *} \mathrm{p}<0.001\right)$. GraphPad Prism (La Jolla, California) was used to plot graphs and to analyse the data.

\section{Discussion}

\section{The effect of p38 in LPS induced inflammation in CF}

CF lung disease is characterised by increased responses to bacterial infections, mainly driven by TLRs and NF- $\kappa B$ signalling. A key feature of CF inflammation is the neutrophil-dominated response, mediated by higher than normal levels of the chemoattractant IL-8. In non-CF airways, TLR activation leads to transcription factor NF- $\kappa B$ induced translation of IL-8. Within the TLR-NF- $\kappa B$ activation pathway, A20 is one of the key negative regulators of this response, ultimately leading to a timely termination of the inflammation. Induction of A20 by the plant derived diterpenoid gibberellin $\left(\mathrm{GA}_{3}\right)$ decreases NF- $\mathrm{\kappa B}$ activation and subsequent IL-8 release in airway epithelial cells [42]. However, CF airways cells not only have lower basal and stimulated levels of A20 than non-CF cells, their response to gibberellin and other A20 inducing drugs [41] is blunted, especially in primary airway epithelial cells. Subsequently, CF cells show no significant reduction in IL-8 release in response to LPS when pre-treated with these A20 inducing drugs. More so, we found that when cells are pre-treated with $\mathrm{GA}_{3}$, cells from some patients show an increase in IL-8 secretion. Additionally, our recent data demonstrated that $\mathrm{CF}$ airway epithelial cells are able to induce and maintain A20 mRNA [41] when stimulated with higher doses of ikarugamycin $(1 \mu \mathrm{m})$, suggesting that $\mathrm{A} 20$ can be upregulated to oppose drug induced apoptosis, but further work is needed to investigate the apoptotic pathways involved.

In inflammation, IL-8 translation can be maintained at higher levels by mRNA stabilisation through the activity of MAPK p38 [45]. Global gene expression in immortalized human $\mathrm{CF}$ and non-CF airway cells showed an inflammatory gene signature involving MAPK signalling and the hyper-inflammatory phenotype in response to microbial stimulation was found to be dependent on p38 activity [46]. CF lung biopsies showed increased immunoreactivity for p38 MAPK activity markers and CFTR Phe508del/Phe508del airway epithelial cells lines (NuLi) confirmed a further increase in p38 activity when stimulated with $P$. aeruginosa [47]. Furthermore, the p38-MAPK inhibitor SB203580 significantly controlled LPS induced inflammation in CF nasal biopsies tissues [48] rendering the p38 signalling pathway as a possible therapeutic target [49].

Our study investigating the induction of the NF- $\kappa B$ regulator A20 in PNECs indicated individual differences with respect to basal 
and LPS stimulated p38 mRNA expression. The effect of the A20 inducer gibberellic acid on p38 MAPK signalling is not known, but our observational data suggest that in those patients with higher basal p38 expression treatment with $\mathrm{GA}_{3}$ has a pro-inflammatory effect (increase IL-8 release). The inhibition of NF- $\kappa B$ signalling via A20 at the levels of TRAF6 may also affect p38 MAPK (Figure 1).

Moreover, in activated macrophages (RAW cells) p38 has been described as a transcriptional regulator of A20 via the transcription factor C/EBPbeta [50]. Our observation that increased basal p38 expression is associated with lower A20 induction cannot be explained by $\mathrm{p} 38$ increasing the transcription factor binding to the A20 promoter. Furthermore, although CF PNECs responding to $\mathrm{GA}_{3}+\mathrm{LPS}$ with a reduction of IL-8 $(24 \mathrm{~h})$ also show the highest levels of GA + LPS induced p38 expression (peak at $4 \mathrm{~h}$ ), this does not result in sufficient induction of A20, which may suggest another mechanism for repressing A20 induction. However, as we had only very few CF PNECs in our subgroups, we were only able to describe our observations here. Further investigations are needed to be able to apply statistical analyses to the p38 expression levels in CF PNECs.

In summary, our data suggest that in CF airway epithelial cells NF$\kappa \mathrm{B}$ together with other pro-inflammatory pathways such as MAPK-p38 are responsible for the sustained high levels of pro-inflammatory cytokine release when stimulated with LPS. A20 inducing compounds such as $\mathrm{GA}_{3}$ have been shown to have anti-inflammatory effects through reducing NF- $\kappa \mathrm{B}$ activation [41] but in CF PNECs the otherwise antiinflammatory $\mathrm{A} 20$ induction by $\mathrm{GA}_{3}$ might be modified or overwritten by pre-existing p38 levels, resulting in a pro-inflammatory effect of $\mathrm{GA}_{3}$, but the underlying mechanisms still need further investigation. More so, the cause for the basal and LPS stimulated lack of A20 in CF airway epithelial cells is still unknown. Recent data suggest that factors regulating A20 translation may also play a role in disease or cell specific A20 levels [51]. However, our data suggest a possible role for personalised anti-p38 treatment as identified high p38 expressing CF patients may benefit from therapeutics targeting p38 as described by Raia et al. [48].

\section{Acknowledgement}

The authors would like to express their thanks to all CF patients and volunteers that took part in this study.

\section{References}

1. UK, CFT. Cystic fibrosis - Strength in numbers. In UK cystic fibrosis registry 2014 Annual Data Report.

2. Dodge JA, Lewis PA, Stanton M, Wilsher J (2007) Cystic fibrosis mortality and survival in the UK: 1947-2003. Eur Respir J 29: 522-526.

3. Lyczak JB, Cannon CL, Pier GB (2002) Lung infections associated with cystic fibrosis. Clinical Microbiol Rev 15: 194-222.

4. Rowe SM, Liu B, Hill A, Hathorne H, Cohen M, et al. (2013) Optimizing nasa potential difference analysis for CFTR modulator development: Assessment of ivacaftor in CF subjects with the G551D-CFTR mutation. PloS One 8: e66955

5. Moss RB, Flume PA, Elborn JS, Cooke J, Rowe SM, et al. (2015) Efficacy and safety of ivacaftor in patients with cystic fibrosis who have an Arg117His-CFTR mutation: A double-blind, randomised controlled trial. The Lancet 3: 524-533.

6. Wainwright CE, Elborn JS, Ramsey BW, Marigowda G, Huang X, et al. (2015) Lumacaftor-Ivacaftor in patients with cystic fibrosis homozygous for Phe508del CFTR. N Engl J Med 373: 1783-1784.

7. Rowe SM, Heltshe SL, Gonska T, Donaldson SH, Borowitz G, et al. (2014) Clinical mechanism of the cystic fibrosis transmembrane conductance regulator potentiator ivacaftor in G551D-mediated cystic fibrosis. Am J Respir Crit Care Med 190: 175-184.

8. Barry PJ, Jones AM (2015) New and emerging treatments for cystic fibrosis. Drugs 75: 1165-1175.
9. Greene CM, Caroll TP, Smith SGJ, Taggart CC Devaney J, et al. (2005) TLR induced inflammation in cystic fibrosis and non-cystic fibrosis airway epithelial cells. J Immunol 174: 1638-1646.

10. Hauber HP, Tulic MK, Tsicopoulos A, Wallaert B, Olivenstein R, et al. (2010) Toll-like receptors 4 and 2 expression in the bronchial mucosa of patients with cystic fibrosis. Can Respir J 12: 13-18.

11. John G, Yildirim AO, Rubin BK, Gruenert DC, Henke MO (2010) TLR-4mediated innate immunity is reduced in cystic fibrosis airway cells. Am J Respir Cell Mol Biol 42: 424-431.

12. Kelly C, Canning P, Buchanan PJ, Williams MT, Brown V, et al. (2013) Toll-like receptor 4 is not targeted to the lysosome in cystic fibrosis airway epithelia cells. Am J Physiol 304: L371-382.

13. Blackwell TS, Stecenko AA, Christman JW (2001) Dysregulated NF-kappaB activation in cystic fibrosis: Evidence for a primary inflammatory disorder. Am J Physiol Lung Cell Mol Physiol 281: L69-L70.

14. Cohen TS, Prince A (2012)Cystic fibrosis: A mucosal immunodeficiency syndrome. Nat Med 18: 509-519.

15. Ma A, Malynn BA (2012) A20: linking a complex regulator of ubiquitylation to immunity and human disease. Nat Rev Immunol 12: 774-785.

16. Opipari AW Jr, Hu HM, Yabkowitz R, Dixit VM (1992) The A20 zinc finger protein protects cells from tumor necrosis factor cytotoxicity. J Biol Chem 267:1242412427.

17. Barmada MM, Brant SR, Nicolae DL, Achkar JP, Panhuysen Cl, et al. (2004) A genome scan in 260 inflammatory bowel disease-affected relative pairs Inflamm Bowel Dis 10: 513-520.

18. Vereecke L, Beyaert R, van Loo G (2009) The ubiquitin-editing enzyme A20 (TNFAIP3) is a central regulator of immunopathology. TrendsImmunol 30: 383391.

19. Shembade N, Harhaj EW (2012) Regulation of NF-kappaB signaling by the A20 deubiquitinase. Cell Mol Immunol 9: 123-130.

20. Lee EG, Boone DL, Chai S, Libby SL, Chien M, et al. (2000) Failure to regulate TNF-induced NF-kappaB and cell death responses in A20-deficient mice. Science 289: 2350-2354

21. Gon Y, Asai Y, Hashimoto S, Mizumura K, Jibiki I, et al. (2004) A20 inhibits tolllike receptor 2- and 4-mediated interleukin-8 synthesis in airway epithelial cells. Am J Respir Cell Mol Biol 31: 330-336.

22. Tiesset H, Pierre M, Desseyn JL, Guery B, Beermann C, et al. (2009) Dietary (n3) polyunsaturated fatty acids affect the kinetics of pro- and anti-inflammatory responses in mice with Pseudomonas aeruginosa lung infection. J Nutr 139 82-89.

23. Kelly C, Williams MT, Mitchell K, Elborne JS, Ennis M, et al. (2013) Expression of the nuclear factor-kappaB inhibitor A20 is altered in the cystic fibrosis epithelium. Eur Respir J 41: 1315-1323.

24. Kelly C, Williams MT, Elborn JS, Ennis M, Schock BC (2013) Expression of the inflammatory regulator A20 correlates with lung function in patients with cystic fibrosis. J Cyst Fibros 12: 411-415.

25. Onose A, Hashimoto S, Hayashi S, Maruoka S, Kumasawa F, et al. (2006) An inhibitory effect of A20 on NF-kappaB activation in airway epithelium upon influenza virus infection. Eur J Pharmacol 541: 198-204.

26. Maelfait J, Roose K, Vereecke L, Guire CM, Sze M, et al. (2016) A20 deficiency in lung epithelial cells protects against influenza A virus infection. PLoS pathogens 12: e1005410.

27. Maelfait J, Roose K, Bogaert P, Sze M, Saelens X, et al. (2012) A20 (Tnfaip3) deficiency in myeloid cells protects against influenza $A$ virus infection. PLoS pathogens 8: e1002570.

28. Duong $\mathrm{BH}$, Onizawa $\mathrm{M}$, Oses-Prieto JA, Advincula $\mathrm{R}$, Burlingame $\mathrm{A}$, et al. (2015) A20 restricts ubiquitination of pro-interleukin-1beta protein complexes and suppresses NLRP3 inflammasome activity. Immunity 42: 55-67.

29. Catrysse L, Vereecke L, Beyaert R, van Loo G (2014) A20 in inflammation and autoimmunity. Trends Immunol 35: 22-31.

30. Wang J, Ouyang Y, Guner Y, Ford HR, Grishin AV (2009) Ubiquitin-editing enzyme A20 promotes tolerance to lipopolysaccharide in enterocytes. J Immunol 183: 1384-1392. 
31. Chen C, Yang G, Geng Xr, Wang X, Liu Z, et al. (2012) TNFAIP3 facilitates degradation of microbial antigen SEB in enterocytes. PloS one 7, e45941.

32. Huang P, Geng XR, Yang G, Chen C, Liu Z, et al. (2012) Ubiquitin E3 ligase A20 contributes to maintaining epithelial barrier function. Cell Physiol Biochem 30: 702-710.

33. Vereecke L, Sze M, Mc Guire C, Rogiers B, Chu Y, et al. (2010) Enterocytespecific A20 deficiency sensitizes to tumor necrosis factor-induced toxicity and experimental colitis. J Exp Med 207: 1513-1523.

34. Shi CS, Kehrl JH (2010) TRAF6 and A20 regulate lysine 63-linked ubiquitination of Beclin-1 to control TLR4-induced autophagy. Sci Signal 3: ra42.

35. Yamaguchi N, Yamaguchi $N$ (2015) The seventh zinc finger motif of A20 is required for the suppression of TNF-alpha-induced apoptosis. FEBS Lett 589: 1369-1375.

36. Fukaya M, Brorsson CA, Meyerovich K, Catrysse L, Vanzela EC, et al. (2016) A20 inhibits beta-cell apoptosis by multiple mechanisms and predicts residual beta-cell function in type 1 diabetes. Mol Endocrinol 30: 48-61.

37. Won M, Park KA, Byun HS, Sohn KC, Kim YR, et al. (2010) Novel anti-apoptotic mechanism of A20 through targeting ASK1 to suppress TNF-induced JNK activation. Cell Death Differ 17: 1830-1841.

38. Jin Z, Li Y, Pitti R, Lawrence D, Pham VC, et al. (2009) Cullin3-based polyubiquitination and p62-dependent aggregation of caspase-8 mediate extrinsic apoptosis signaling. Cell 137: 721-735.

39. Onizawa M, Oshima S, Schulze-Topphoff U, Osses-Prieto JA, Lu T, et al. (2015) The ubiquitin-modifying enzyme A20 restricts ubiquitination of the kinase RIPK3 and protects cells from necroptosis. Nat Immunol 16: 618-627.

40. Schuijs MJ, Williart MA, Vergote K, Gras D, Deswarte K, et al. (2015) Farm dust and endotoxin protect against allergy through A20 induction in lung epithelial cells. Science 349: 1106-1110.

41. Malcomson $B$, Wilson $H$, Veglia $E$, Thillaiyampalam $G$, Barsden $R$, et al (2016) Connectivity mapping (ssCMap) to predict A20-inducing drugs and their antiinflammatory action in cystic fibrosis. Proc Natl Acad Sci USA 113: E3725-E3734.

Citation: McCallum K, El Banna A, Ennis M, Schock BC (2016) Chronic Inflammation in CF Airways - A Persistent Issue for A20. J Genet Syndr Gene Ther 7: 313. doi: $10.4172 / 2157-7412.1000313$
42. Reihill JA, Malcomson B, Bertelsen A, Cheung S, Czerwiec A, et al. (2015) Induction of the inflammatory regulator A20 by gibberellic acid in airway epithelial cells.Br J Pharmacol 173: 778-789.

43. Tan BM, Zammit NW, Yam AO, Slattery R, Walters SN, et al. (2013) Baculovira inhibitors of apoptosis repeat containing (BIRC) proteins fine-tune TNFinduced nuclear factor kappaB and c-Jun $\mathrm{N}$-terminal kinase signalling in mouse pancreatic beta cells. Diabetologia 56: 520-532.

44. Zhang SD, Gant TW (2009) sscMap: An extensible Java application for connecting small-molecule drugs using gene-expression signatures. BMC bioinformatics 10: 236

45. Jundi K, Greene CM (2015) Transcription of interleukin-8: How altered regulation can affect cystic fibrosis lung disease. Biomolecules 5: 1386-1398.

46. Blohmke CJ, Mayer ML, Tang AC, Hirschfeld AF, Fjell CD, et al. (2012) Atypical activation of the unfolded protein response in cystic fibrosis airway cells contributes to p38 MAPK-mediated innate immune responses. J Immunol 189 5467-5475.

47. Berube J, Roussel L, Nattagh L, Rousseau S (2010) Loss of cystic fibrosis transmembrane conductance regulator function enhances activation of p38 and ERK MAPKs, increasing interleukin-6 synthesis in airway epithelial cells exposed to Pseudomonas aeruginosa. J Biol Chem 285: 22299-22307.

48. Raia V, Maiuri L, Ciacci C, Ricciardelli I, Vacca L, et al. (2005) Inhibition of p38 mitogen activated protein kinase controls airway inflammation in cystic fibrosis. Thorax 60: 773-780

49. Zhang Z, Reenstra W, Weiner DJ, Louboutin JP, Wilson JM (2007) The p38 mitogen-activated protein kinase signaling pathway is coupled to toll-like receptor 5 to mediate gene regulation in response to $P$ seudomonas aeruginosa infection in human airway epithelial cells. Infect Immun 75: 5985-5992.

50. Lai TY, Wu SD, Tsai MH, Chuang EY, Chuang LL, et al. (2013) Transcription of Tnfaip3 is regulated by NF-kappaB and p38 via C/EBPbeta in activated macrophages. PloS one 8: e73153.

51. Tiruppathi C, Soni D, Wang DM, Xue J, Singh V, et al. (2014) The transcription factor DREAM represses the deubiquitinase A20 and mediates inflammation. Nat Immunol 15: 239-247.
OMICS International: Publication Benefits \& Features

Unique features:

- Increased global visibility of articles through worldwide distribution and indexing

- Showcasing recent research output in a timely and updated manner

Special issues on the current trends of scientific research

Special features:

$700+$ Open Access Journa

$50,000+$ editorial tean

Rapid review process

Quality and quick editorial, review and publication processing

Indexing at major indexing services

Sharing Option: Social Networking Enabled

Authors, Reviewers and Editors rewarded with online Scientific Credits

Better discount for your subsequent articles

Submit your manuscripts as E- mail: www.omicsonline.org/submission/ 